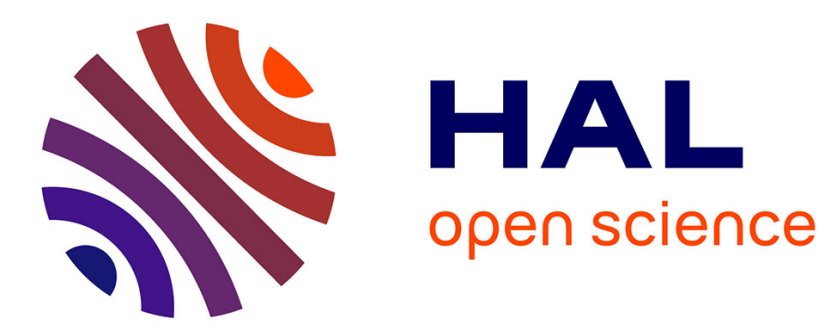

\title{
Heat flow, diffusion and convection in the travelling solvent method
}

\author{
D. Langbein
}

\section{To cite this version:}

D. Langbein. Heat flow, diffusion and convection in the travelling solvent method. Revue de Physique Appliquée, 1977, 12 (2), pp.129-134. 10.1051/rphysap:01977001202012900 . jpa-00244131

\section{HAL Id: jpa-00244131 https://hal.science/jpa-00244131}

Submitted on 1 Jan 1977

HAL is a multi-disciplinary open access archive for the deposit and dissemination of scientific research documents, whether they are published or not. The documents may come from teaching and research institutions in France or abroad, or from public or private research centers.
L'archive ouverte pluridisciplinaire HAL, est destinée au dépôt et à la diffusion de documents scientifiques de niveau recherche, publiés ou non, émanant des établissements d'enseignement et de recherche français ou étrangers, des laboratoires publics ou privés. 


\title{
HEAT FLOW, DIFFUSION AND CONVECTION IN THE TRAVELLING SOLVENT METHOD
}

\author{
D. LANGBEIN \\ Battelle-Institut e. V., Frankfurt/Main, Germany
}

\begin{abstract}
Résumé. - On établit les équations décrivant l'écoulement de la chaleur et des particules durant la croissance cristalline par la méthode THM. Les paramètres suivants sont considérés : les radiations s'échappant par les surfaces, la chaleur de fusion aux interfaces, les modifications de conductivité thermique dans le cristal et le solvant, la vitesse de déplacement de la zone liquide. A partir du profil de température et la concentration de particules au voisinage de l'axe du cristal, il a été possible de trouver des solutions analytiques à ces équations, valables à travers tout le cristal et le solvant. Le flux de chaleur, modifié par la vitesse de déplacement, conduit à un accroissement du gradient de température dans la source par rapport à celui existant dans le matériau en train de cristalliser. La position et la température de la zone fondue et des interfaces sont déterminées par le flux de particules. La conduction thermique produit un nivellement de la température à travers le solvant, un accroissement de la température aux interfaces de dissolution et de cristallisation, ainsi qu'une extension de la zone de solvant. La convection tend à devenir instable et favorise la surfusion. Une gravitation nulle supprimerait la convection. Le flux de chaleur et de particules tendent à se compenser mutuellement et suppriment la surfusion.
\end{abstract}

\begin{abstract}
The equations describing heat and particle flow during crystal growth by the travelling solvent method are developed. The thermal radiation across the surface, the heat of fusion arising at the interfaces, the change in thermal conductivity in the crystal and the solvent, and the travel rate are taken into account. By expanding both the temperature profile and the particle concentration in the vicinity of the crystal axis, analytical solutions are obtained in all crystal and solvent regions. The heat flow enforced by the travel rate causes the temperature gradient in the feed crystal to become steeper than that in the growing crystal. The position and temperature of the dissolving and of the growing interfaces are fixed by the particle flow. The effect of convection is a levelling of the temperature in the solvent, an increase in the temperatures at the dissolving and the growing interfaces, and an extension of the solvent zone. Convection tends to become unstable and favours supercooling. Zero gravitation avoids convection. Heat and particle flow stabilize mutually and suppress supercooling.
\end{abstract}

1. Introduction. - It is the aim of this paper to study the temperature profile, the particle concentration, and the effect of convection during crystal growth by the travelling solvent method. There have been earlier investigations on the temperature profile and the effect of convection [1-4]. However, these show only little flexibility, since numerical methods or expansion in terms of cylindrical Bessel functions have been used. In most cases only the temperature profile has been considered, which implies that the position and temperature of the dissolving and the growing interfaces are already known by observation.

In the following it will be shown that it is the equilibrium between the heat flow and the particle flow which determines position and temperature of the dissolving and the growing interfaces. By expanding the temperature profile and the particle concentration with respect to the distance from the crystal axis we obtain analytical representations in all regions of the crystal and the solvent. They are matched across the crystal-solvent interfaces subject to the boundary conditions that the temperature must be continuous, whereas the heat flow changes by the heat of fusion, and that the particle concentration at the interfaces is related to temperature as given by the liquidus diagram. A second pair of boundaries arises at the heater ends. The change in the external radiation requires different analytical expressions for the temperature profile in the crystal. These have to be matched such that temperature and heat flow are continuous.

Convection results in levelling of the temperature profile in the solvent. We shall study convection by simultaneously increasing the coefficients describing heat and particle diffusion.

2. Basic Equations. - Figure 1 shows the principle of the travelling solvent method and the notation used in the following. The quantities related to the growing 


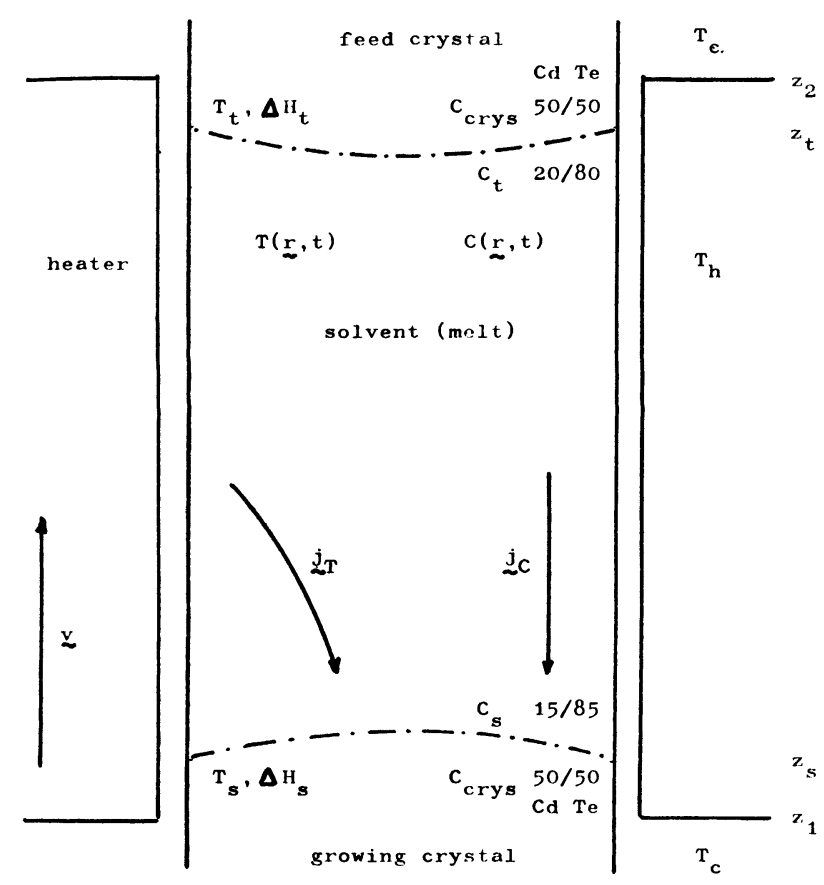

FIG. 1. - Travelling solvent method.

and the dissolving interface carry the subscript $\mathbf{s}$ and $t$, respectively. The respective heater ends are denoted by subscripts 1 and 2 . The following symbols are used :

$T(\mathbf{r}, t)$ temperature at position $\mathbf{r}$ and time $t$,

$T_{\mathrm{s}}$ temperature at the growing interface,

$T_{t}$ temperature of the dissolving interface,

$\mathbf{j}_{\mathbf{T}} \quad$ heat flow,

$\Delta H_{\mathrm{s}}$ heat of solidification,

$\Delta H_{\mathrm{t}}$ heat of fusion,

$\lambda$ thermal conductivity,

$x$ heat capacity per volume,

$C(\mathbf{r}, t)$ particle concentration at position $\mathbf{r}$ and time $t$,

$C_{\mathrm{s}} \quad$ particle concentration at the growing interface,

$C_{\mathrm{t}}$ particle concentration at the dissolving interface,

$C_{\text {crys }}$ particle concentration in the crystal.

$\mathbf{j}_{\mathrm{c}} \quad$ particle flow,

$D$ particle diffusion coefficient,

$T_{\mathrm{h}}$ heater temperature,

$T_{\mathrm{c}} \quad$ cooler temperature,

v travel rate.

When the travelling solvent method is applied to growing CdTe crystals with the solvent containing $\mathrm{Te}$ in excess, we understand that the terms particle concentration and particle flow refer to the $\mathrm{Cd}$ atoms.

The relative motion of heater and sample with the travel rate $\mathbf{v}$ implies that the temperature and concentration at position $\mathbf{r}$ and time $t$ equal temperature and concentration at position $\mathrm{r}+\mathrm{v} d t$ and time $t+\mathrm{d} t$ :

$$
\begin{aligned}
& T(\mathbf{r}, t)=T(\mathbf{r}-\mathbf{v} t) \\
& C(\mathbf{r}, t)=C(\mathbf{r}-\mathbf{v} t) .
\end{aligned}
$$

The constitutive equations for heat and particle flow are not changed by the travel rate $\mathbf{v}$, so that

$$
\begin{aligned}
& \mathbf{j}_{\mathrm{T}}=-\lambda \operatorname{grad} T(\mathbf{r}, t) \\
& \mathbf{j}_{\mathrm{C}}=-D \operatorname{grad} C(\mathbf{r}, t) .
\end{aligned}
$$

In setting up the equations describing heat and particle conservation we have to take into account the heat of fusion used and recovered at the dissolving interface $z_{\mathrm{t}}$ and the growing interface $z_{\mathbf{s}}$, yielding

$$
\begin{aligned}
\operatorname{div} \mathbf{j}_{\mathrm{T}}+x(\partial T / \partial t)+v\left[\Delta H_{\mathrm{t}} \delta\left(z-z_{\mathrm{t}}\right)-\right. \\
\left.-\Delta H_{\mathrm{s}} \delta\left(z-z_{\mathrm{s}}\right)\right]=0,
\end{aligned}
$$

and the change in particle concentration arising at the interfaces, yielding

$$
\begin{aligned}
\operatorname{div} \mathbf{j}_{\mathrm{C}}+\partial C / \partial t+v\left[\Delta C_{\mathrm{s}} \delta\left(z-z_{\mathrm{s}}\right)-\right. \\
\left.-\Delta C_{\mathrm{t}} \delta\left(z-z_{\mathrm{t}}\right)\right]=0 .
\end{aligned}
$$

Equations (3) to (6) have to be solved subject to the boundary conditions that heat is radiated from the heater to the sample and from the sample to the exterior and that the particle flow vanishes within the feed crystal and the growing crystal. The particle diffusion from the dissolving to the growing interface generally requires that the temperature $T_{\mathrm{t}}$ at the dissolving interface is higher than the temperature $T_{\mathrm{s}}$ at the growing interface. This opposite trend of heat flow and particle flow determines the position and temperature of both interfaces.

3. Expansion around crystal axis. - Before solving eqs. (3) to (6) it should be noted that there are a few cases in which the equations of heat conduction and particle diffusion can be solved rigorously. A case closely related to the present situation is heat conduction from a ring heater. If the ring heater is located in a medium of thermal conductivity $\lambda_{t}(=$ solvent) and if the interface with a second medium of thermal conductivity $\lambda_{\mathrm{s}}(=$ crystal) happens to be an isotherm, we obtain

$$
T(\mathbf{r})=T_{\mathrm{c}}+\frac{Q}{2 \pi^{2} \lambda_{\mathrm{s}}} \frac{K(m)}{\sqrt{z^{2}+(r+R)^{2}}} \text { in the crystal }
$$

$T(\mathbf{r})=T_{\mathrm{h}}+\frac{Q}{2 \pi^{2} \lambda_{\mathrm{t}}} \frac{K(m)}{\sqrt{z^{2}+(r+R)^{2}}}$ in the solvent

where

$R \quad=$ radius of the ring heater,

$Q \quad=$ heat production per time,

$K(m)=$ complete elliptic integral of the first kind, and $m=4 r R /\left(z^{2}+(R+r)^{2}\right)$.

The isotherms resulting from eqs. (7) and (8) with $\lambda_{\mathrm{t}} / \lambda_{\mathrm{s}}=2$ and the temperature profiles along the axis and along the surface of a cylinder of radius $0.8 R$ are 
shown in figure 2. The shape of the isotherms obtained in the presence of a ring heater is typical also of more realistic heater shapes. The isotherms in the case of a

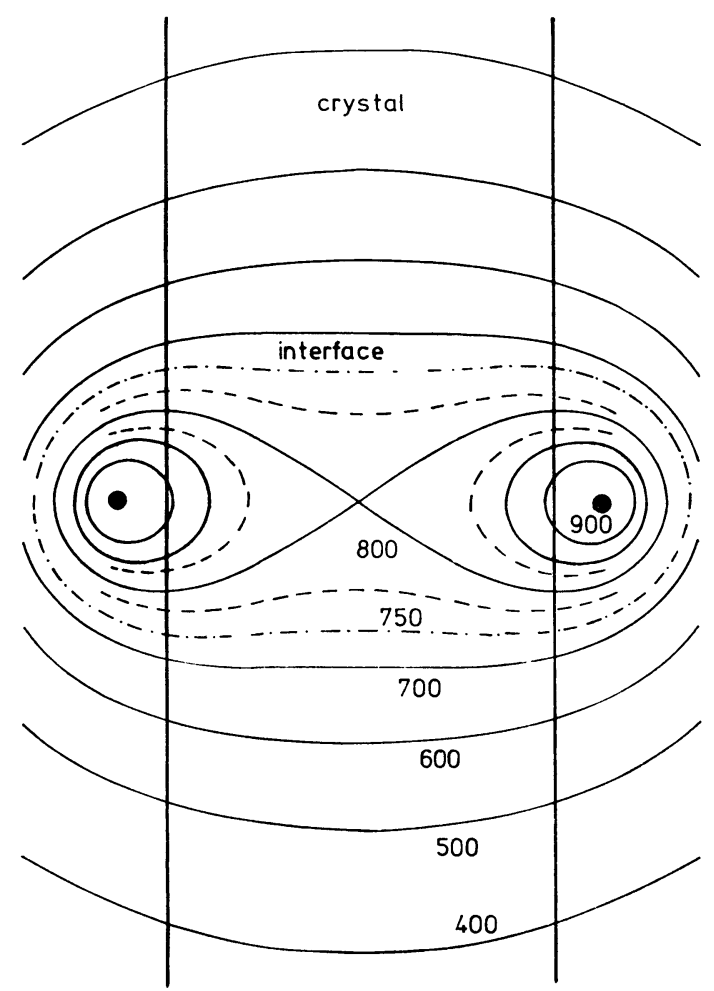

(a)

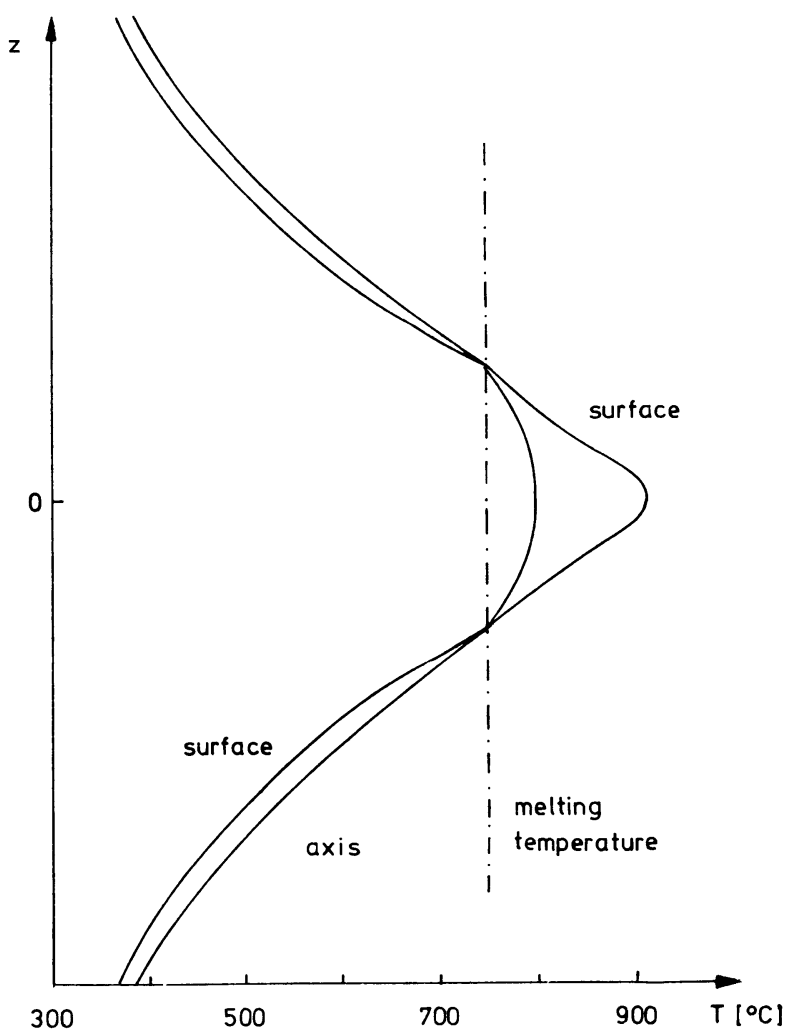

(b)

FIG. 2. - Temperature profile in the presence of a ring heater : a) isotherms ; $b$ ) temperature at axis and surface. cylinder heater can be obtained by integration from eqs. (7) and (8).

The internal portion of the isotherms in figure 2 is satisfactorily described by expanding eqs. (7) and (8) with respect to the distance $r$ from the cylinder axis. The first term of this expansion gives the temperature at the axis, whereas the second term provides the curvature of the isotherms and the radial heat flow. In the following we restrict ourselves to an expansion with respect to the distance $r$ from the cylinder axis.

Excluding the interfaces we have from eqs. (1) to (6)

$$
\begin{aligned}
\lambda \operatorname{div} \operatorname{grad} T(\mathbf{r}, t)+v x(\partial T(\mathbf{r}, t) / \partial z) & =0 \\
D \operatorname{div} \operatorname{grad} C(\mathbf{r}, t)+v \partial C(\mathbf{r}, t) / \partial z & =0 .
\end{aligned}
$$

Putting

$$
\begin{aligned}
& T(\mathbf{r}-\mathbf{v} t)=\sum_{n=0}^{\infty} r^{2 n} T_{2 n}(z) \\
& C(\mathbf{r}-\mathbf{v} t)=\sum_{n=0}^{\infty} r^{2 n} C_{2 n}(z)
\end{aligned}
$$

we obtain

$\frac{\mathrm{d}^{2}}{\mathrm{~d} z^{2}} T_{2 n}(z)+\frac{v x}{\lambda} \frac{\mathrm{d}}{\mathrm{d} z} T_{2 n}(z)+(2 n+2)^{2} T_{2 n+2}(z)=0$

$\frac{\mathrm{d}^{2}}{\mathrm{~d} z^{2}} C_{2 n}(z)+\frac{v}{D} \frac{\mathrm{d}}{\mathrm{d} z} C_{2 n}(z)+(2 n+2)^{2} C_{2 n+2}(z)=0$.

The radial heat flow is given by the heat radiation from the heater to the sample and from the sample to the exterior. The radial particle flow equals zero. Restricting ourselves to the terms $n=0$ and $n=1$ in the series (11) and (12) we find

$$
\begin{aligned}
& \frac{\mathrm{d}^{2}}{\mathrm{~d} z^{2}} T_{0}(z)+\frac{v x}{\lambda} \frac{\mathrm{d}}{\mathrm{d} z} T_{0}(z)=\gamma\left(T_{0}^{4}(z)-T_{\mathrm{h}, \mathrm{c}}^{4}\right) \\
& \frac{\mathrm{d}^{2}}{\mathrm{~d} z^{2}} C_{0}(z)+\frac{v}{D} \frac{\mathrm{d}}{\mathrm{d} z} C_{0}(z)=0
\end{aligned}
$$

where $\gamma=2 \sigma \varepsilon / R \lambda$ is the ratio of heat radiation over heat conduction, i. e. $\sigma$ is the Stephan-Boltzmann constant, $\varepsilon$ is the emissivity, $R$ is the radius of the sample. $T_{\mathrm{b}}$ equals $T_{\mathrm{b}}$ in the heater and $T_{\mathrm{c}}$ in the cooler.

4. Heat and particle flow. - At zero travel rate $\mathbf{v}$ (in the absence of the term $\mathrm{d} T_{0}(z) / \mathrm{d} z$ ), eq. (15) is readily integrated by multiplication by $\mathrm{d} T_{0}(z) / \mathrm{d} z$, as follows

$\frac{1}{2}\left(\frac{\mathrm{d} T_{0}(z)}{\mathrm{d} z}\right)^{2}=\gamma\left[\frac{1}{5} T_{0}^{5}(z)-T_{\mathrm{h}, \mathrm{c}}^{4} T_{0}(z)+\right.$ const $]$.

The integration constant in eq. (17) in the cooler 
region results from the condition that $T_{\mathrm{c}}$ is approached asymptotically. The respective integration constant in the heater region follows from the continuity of the temperature $T_{0}(z)$ at the crystal-solvent interfaces. It turns out convenient to relate the integration constant in the heater region to the maximum temperature adopted.

By substituting eq. (17) into eq. (15) and expanding with respect to $T_{0}(z)-T_{\mathrm{c}}$ in the cooler region and with respect to $T_{0}(z)-T_{\mathrm{m}}$ in the heater region we obtain

$$
T_{0}(z)=T_{\mathrm{c}}\left[\operatorname{coth}\left(\gamma^{1 / 2} T_{\mathrm{c}}^{3 / 2} \pm \frac{1}{2} \beta\right) z\right]^{2}
$$

in the cooler region and

$$
\begin{aligned}
T_{\mathrm{m}}-T_{0}(z) & =\frac{T_{\mathrm{h}}^{4}-T_{\mathrm{m}}^{4}}{2 T_{\mathrm{m}}^{3}} \times \\
\times & {\left[\sinh \left(\gamma^{1 / 2} T_{\mathrm{m}}^{3 / 2}\left(z \mp \frac{1}{6} \beta z^{2}\right)\right)\right]^{2} }
\end{aligned}
$$

in the heater region, where $\beta=v x / \lambda$.

The temperature $T_{0}(z)$ at the crystal axis increases exponentially on both sides of the heater. The upper sign in front of $\beta$ in eqs. (18) and (19) refers to the feed crystal, the lower sign to the growing crystal. The exponential increase in the feed crystal is steeper than the exponential decrease in the growing crystal owing to the heat flow enforced by the travel rate. In the heater region, the temperature gradient is steeper in the regrown crystal than in the feed crystal.

The two analytical expressions (18) and (19) for the temperature $T_{0}(z)$ at the crystal axis have to be matched across the heater ends $z_{1}$ and $z_{2}$ such that temperature and heat flow are continuous. Across the dissolving and the growing interfaces two expressions (19), distinguished by different maximum temperatures $T_{\mathrm{m}}$ and different thermal conductivities $\lambda_{\mathrm{t}}$ and $\lambda_{\mathrm{s}}$ have to be matched such that the temperature is continuous, whereas the heat flow changes by the heat of fusion. This is demonstrated in figure 3. The lefthand side of figure 3 shows the temperature versus the heat flow, the right-hand side gives the temperature versus the position. An increasing travel rate generally lowers the temperature $T_{2}$ at the heater end on the side of the feed crystal relative to the temperature $T_{1}$ at the heater end on the side of the growing crystal. Simultaneously, the position of maximum temperature is shifted towards the growing crystal.

Integration of eq. (16) readily yields

$$
C_{0}(z)=c_{1} \exp (-v z / D)+c_{2}
$$

where $c_{1}$ and $c_{2}$ are integration constants. The concentration $C_{0}(z)$ decreases exponentially from the dissolving to the growing interface. The relaxation length equals the travel rate over the diffusion coefficient.

The boundary condition requiring that the particle

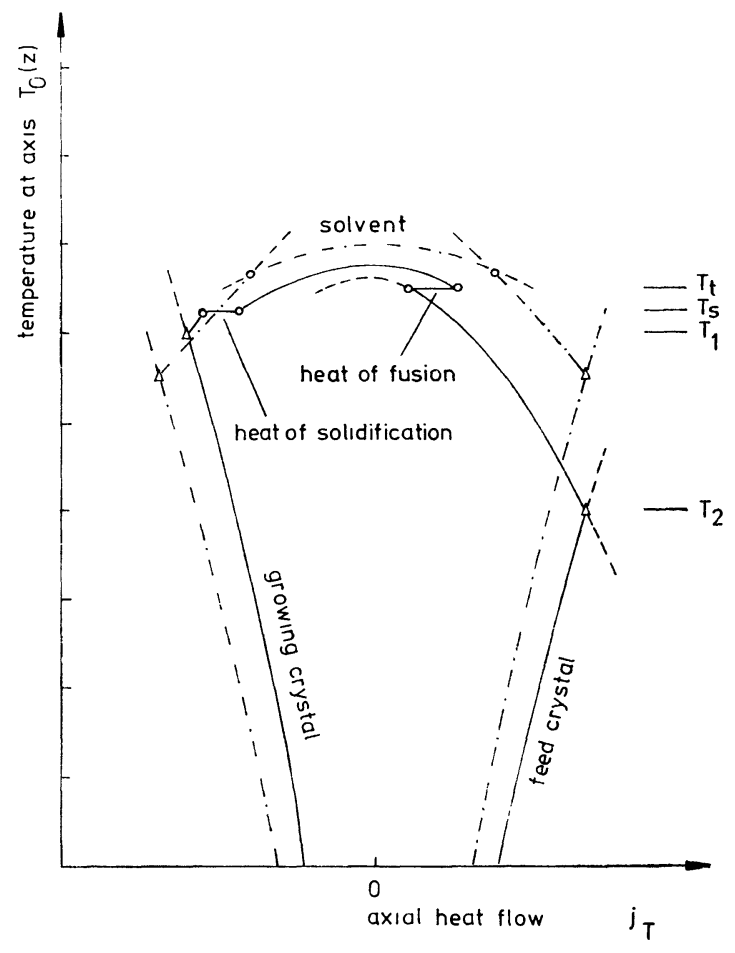

(a)

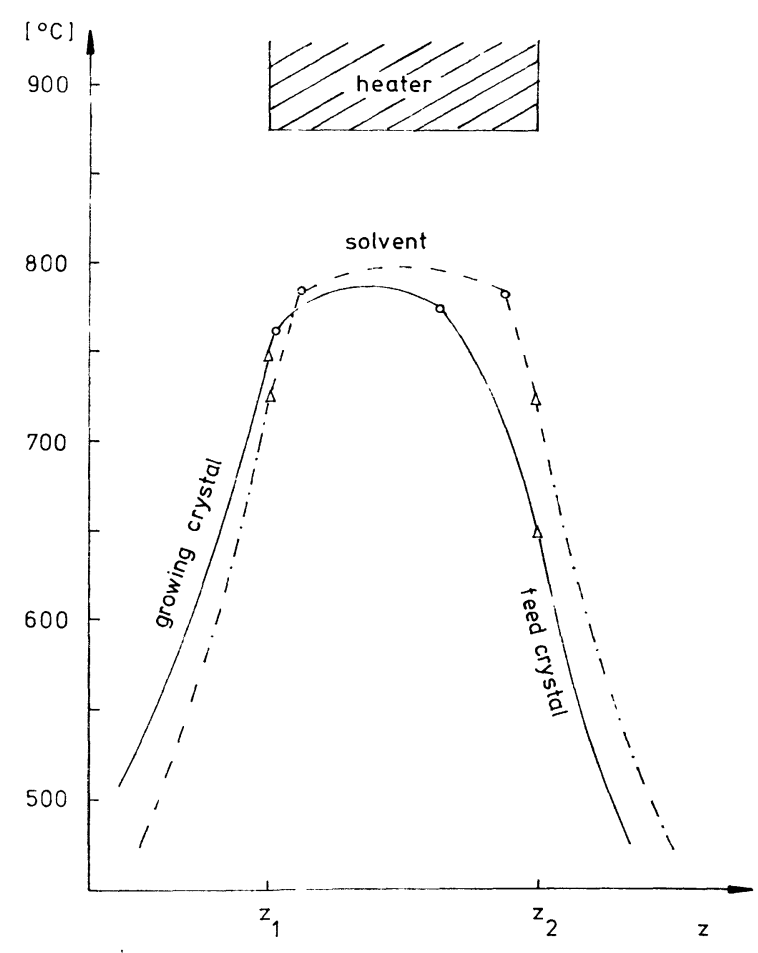

(b)

Fig. 3. - Temperature profile and heat flow at $v=0(-.-.-)$ and $v>0(-)$.

flow at the dissolving and the growing interfaces equals $C_{\mathrm{t}}-C_{\text {crys }}$ and $C_{\mathrm{s}}-C_{\text {crys }}$, respectively, yields

$$
z_{\mathrm{t}}-z_{\mathrm{s}}=\frac{D}{v} \ln \frac{C_{\mathrm{crys}}-C_{\mathrm{s}}}{C_{\mathrm{crys}}-C_{\mathrm{t}}} .
$$


For the total excess of solvent we obtain

$$
\int_{z_{\mathrm{s}}}^{z_{\mathrm{t}}} \mathrm{d} z \frac{C_{\mathrm{crys}}-C_{0}(z)}{C_{\mathrm{crys}}}=\frac{D}{v} \frac{C_{\mathrm{t}}-C_{\mathrm{s}}}{C_{\mathrm{crys}}}
$$

eqs. (21) and (22) together with eqs. (18) and (19) and the liquidus diagram shown in figure 4 fully describe the concentration and temperature profile, including the position and temperature of the dissolving and the growing interfaces.

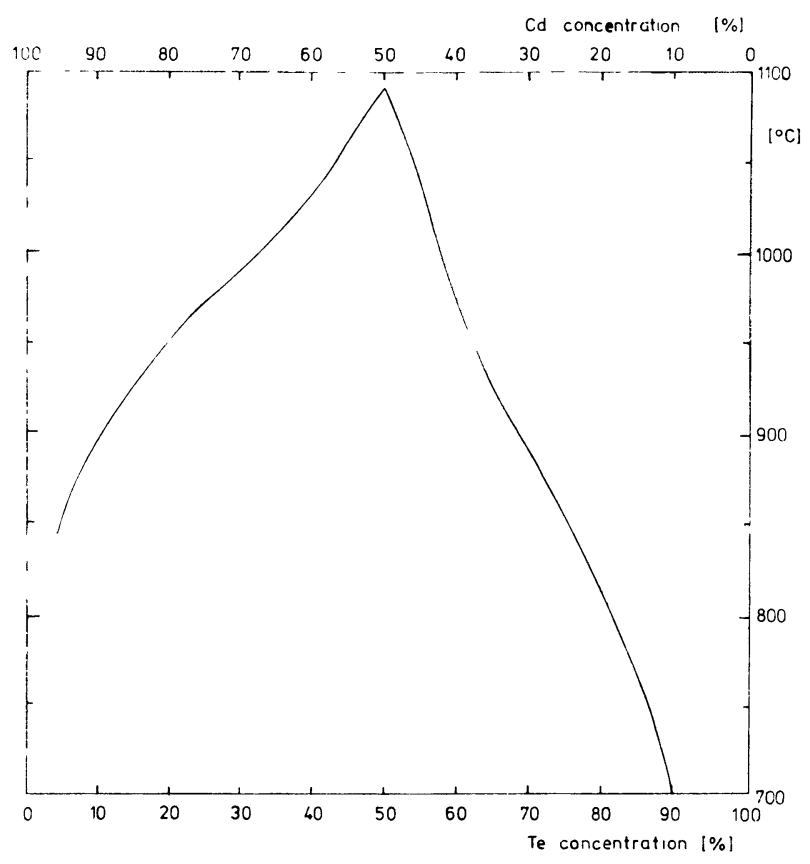

FIG. 4. - Liquidus diagram of CdTe.

Figure 5 illustrates the temperature profile resulting in the case of CdTe. Parameter of the different curves is the temperature $T_{\mathrm{t}}$ of the dissolving interface or else the heater length $z_{2}-z_{1}$. The heater ends are marked by triangles, the crystal-solvent interfaces by circles. With decreasing heater length we find the growing interface clearly to move outside the heater.

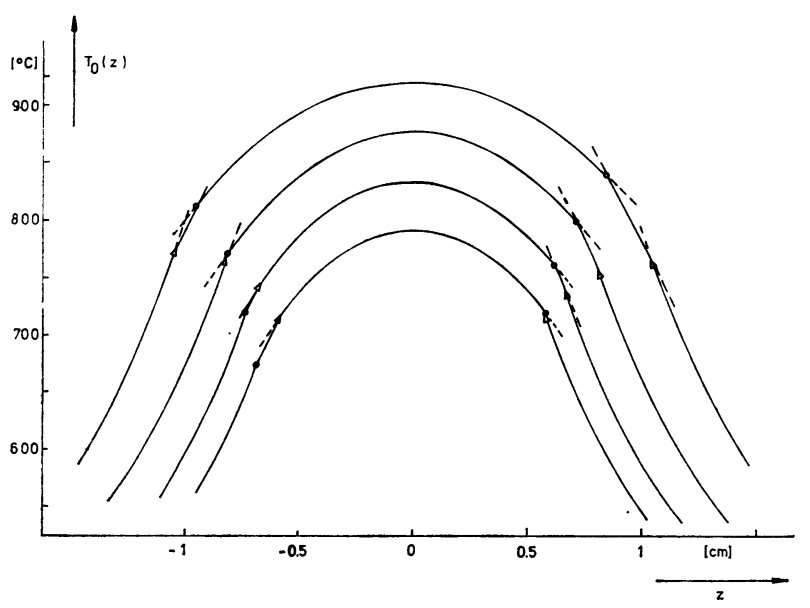

FIG. 5. - Temperature profile in CdTe, $\bigcirc$ dissolving and growing interface, $\triangle$ heater ends. Parameter of the different curies is the temperature at the dissolving interface.
When introducing the expansion (11) of the temperature profile around the axis we noted that the term quadratic in $r$ gives the radial heat flow and the curvature of the isotherms as well. It follows that the growing interface is convex and concave if located in the heater region and in the cooler region, respectively. Since optimum quality of the growing crystal is to be expected for vanishing curvature of the growing interface, the optimum position of the latter is just at the heater end.

5. Convection and zero gravitation. - The temperature $T_{\mathrm{t}}$ at the dissolving interface is generally about $30^{\circ} \mathrm{C}$ higher than the temperature $T_{\mathrm{s}}$ at the growing interface. The maximum temperature $T_{\mathrm{m}}$ in the solvent is about $75^{\circ} \mathrm{C}$ higher than $T_{\mathrm{t}}$. This high internal temperature strongly favours convection. Figure 6

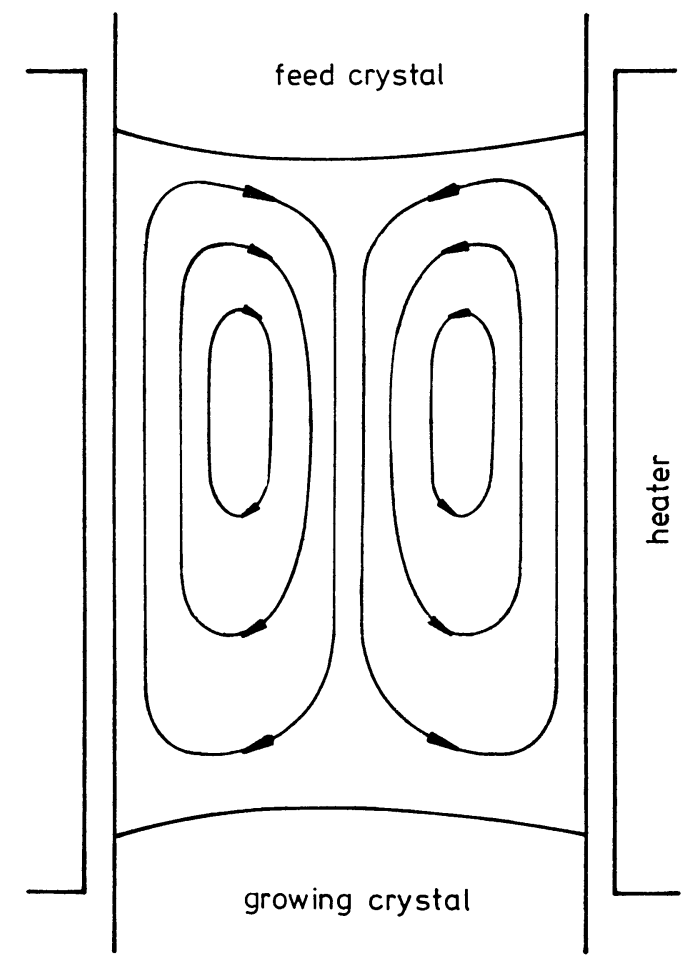

FIG. 6. - Sketch of convection profiles.

shows the temperature profile in the absence of convection and the most likely shape of the resulting convection contours. The cold solvent zone in the vicinity of the axis at the dissolving interface tends to move to the hot solvent zone in the vicinity of the surface in the middle of the heater. The cold solvent zone close to the growing interface attempts to resists this convection but dœs not fully succeed. Thus, convection is expected to be more effective close to the dissolving interface than close to the growing interface.

In order to demonstrate the effect of convection we increase the thermal conductivity $\lambda_{t}$ and the diffusion coefficient $D$ simultaneously by a factor of four. Figure 7 exhibits the resulting temperature profile. We note that 


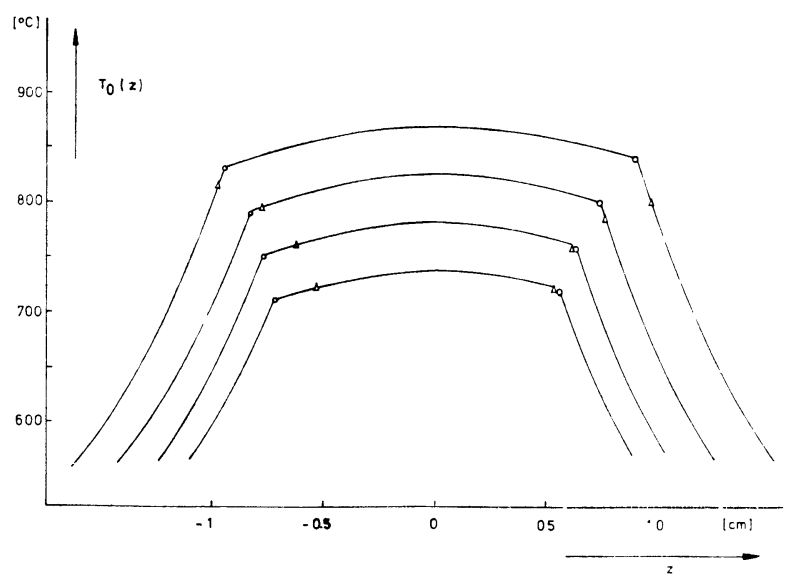

Fig. 7. - Temperature profile at axis in presence of convection $O$ dissolving and growing interface $\triangle$ heater ends.

- convection tries to level the temperature profile in the solvent,

- the average temperature increases,

- the temperatures at the dissolving and at the growing interfaces increase,

- the particle concentration in the solvent is raised,

- the solvent zone is extended,

- the growing interface is shifted towards the heater end or even out of the heater,
- the temperature gradients in the feed crystal and in the growing crystal increase.

In addition, by levelling the original temperature profile, convection tends to be self-damping. Unstable convection causes temperature fluctuations at the dissolving and the growing interfaces and thus favours supercooling of the growing interface.

The important advantage of zero gravitation is that convection is avoided. In the case of zero gravitation

- it is possible to adjust position and temperature of the dissolving and of the growing interface,

- heat flow and particle flow stabilize mutually,

- instantaneous supercooling of the growing interface entails an increase in particle concentration, which speeds up solidification,

- the interfaces are stabilized.

A further stabilization of the interfaces can be achieved by properly adjusting the profile of the heater temperature. It appears expedient to lower the maximum temperature in the solvent zone by lowering the heater temperature in the center region accordingly.

Acknowledgments. - Die vorliegende Studie wurde mit Mitteln der Bundesrepublik Deutschland im Auftrag des Bundesministers für Forschung und Technologie, vertreten durch den Bereich Projektträgerschaften der DFVLR, gefördert.

\section{References}

[1] Chang, C. E., Ph. D. Dissertation, Univ. Southern California Los Angeles 1973.

[2] BeLl, R. O., J. Electrochem. Soc. 121 (1974) 1366.
[3] WaLd, F. V. and Bell, R. O., J. Crystal Growth 30 (1975) 29.

[4] Yip, V. F. S., Chang, C. E. and Wilcox, W. R., J. Crystal Growth 29 (1975) 69. 